\title{
Compreensão empática e as possíveis contribuições para a pesquisa nos estudos organizacionais: reflexões a partir da experiência do lado estético das organizações
}

\author{
LUMA LOUISE SOUSA LOPES \\ Universidade Estadual do Ceará (UECE) / Programa de Pós-Graduação em Administração, Fortaleza - CE, Brasil
}

ANA SILVIA ROCHA IPIRANGA

Universidade Estadual do Ceará (UECE) / Programa de Pós-Graduação em Administração, Fortaleza - CE, Brasil

JOSÉ JORGE DA SILVA JÚNIOR

Universidade Estadual do Ceará (UECE) / Curso de AdMinistração, ForTAlezA - CE, Brasil

\begin{abstract}
Resumo
O método weberiano da compreensão tem constituído objeto de discussão e debate ao longo do tempo. No entanto, especificamente, a compreensão empática ainda é pouco explorada, especialmente no âmbito do estudo das organizações brasileiras. Após levantamento feito nas principais bases de dados e periódicos abrigados no portal Periódicos Capes, verificamos ser escassa a produção acadêmica que percorre o caminho da compreensão empática, especificamente na área dos Estudos Organizacionais no Brasil. Diante disso, procuramos trazer neste artigo algumas considerações sobre o resgate da compreensão empática na pesquisa. Considerando a abordagem da estética organizacional como pano de fundo, a discussão articulou às bases epistemológicas da compreensão empática proposta pela sociologia weberiana. Esta preconiza que os estudos das Ciências Sociais devem estar ancorados prioritariamente na compreensão do sentido da ação dos indivíduos, de modo que possamos entender por que agem de determinada maneira. Então, refletimos sobre as possíveis contribuições da compreensão empática para a pesquisa, considerando a ideia do pesquisador como peça-chave para a construção do corpus de pesquisa e a plausibilidade do conhecimento, sem necessariamente empreender a ação. Almejamos que este estudo sirva de gatilho para a elaboração de novas discussões sobre as possibilidades de contribuição da compreensão empática para a pesquisa nos Estudos Organizacionais.
\end{abstract}

Palavras-chave: Compreensão empática. Estética. Estudos organizacionais.

Empathic understanding and possible contributions to research in organizational studies: reflections from the experience of the aesthetic side of organizations

\begin{abstract}
The method of Weberian understanding has been the subject of discussion and debate over time. However, specifically, empathic understanding is still little explored, especially in the study of Brazilian organizations. After searching on major databases and journals hosted on the website Periódicos CAPES, we found that there is little academic literature that follows the path of empathic understanding, specifically in the field of Organizational Studies in Brazil. Therefore, we seek to bring in this study some considerations about the rescue of empathic understanding for the research. Considering the approach of organizational aesthetics as a backdrop, the discussion articulates the epistemological foundations of empathic understanding proposed by Weber's sociology. This recommends that studies in the field of Social Sciences are anchored primarily in understanding the meaning of individual action to understand why they act a certain way. Following the discussion, we reflect on the possible contributions that empathic understanding can bring to research, considering the idea of the researcher as a key to building the research corpus and the plausibility of knowledge obtained without necessarily undertaking the action. This article serves as a trigger for the development of other discussions about the possibilities of contribution of empathic understanding for the research in Organization Studies.
\end{abstract}

Keywords: Empathic understanding. Aesthetic. Organizational studies.

Comprensión empática y sus posibles contribuciones para la investigación en los estudios organizacionales: reflexiones a partir de la experiencia de la estética de las organizaciones

\begin{abstract}
Resumen
El método weberiano de la comprensión ha sido objeto de discusión y debate desde hace tiempo. No obstante, específicamente, la comprensión empática todavía es poco explorada, especialmente en el ámbito del estudio de las organizaciones brasileñas. Después del relevamiento realizado en las principales bases de datos y periódicos compilados en el portal Periódicos Capes, verificamos que, específicamente en el área de Estudios Organizacionales en Brasil, es escasa la producción académica sobre la comprensión empática. Por lo tanto, este artículo aporta algunas consideraciones sobre el rescate de la comprensión empática en la investigación. Considerando el abordaje de la estética organizacional como telón de fondo, la discusión articuló las bases epistemológicas de la comprensión empática propuesta por la sociología weberiana. Esta preconiza que los estudios de las Ciencias Sociales deben anclarse prioritariamente en la comprensión del sentido de la acción de los individuos, de modo que podamos entender por qué actúan de determinada manera. Para ello, reflexionamos sobre las posibles contribuciones de la comprensión empática a la investigación, considerando la idea del investigador como pieza clave para la construcción del corpus de investigación y la plausibilidad del conocimiento, sin necesariamente emprender la acción. Esperamos que este estudio sirva como un disparador para la elaboración de nuevas discusiones sobre las posibilidades de contribución de la comprensión empática a la investigación en los Estudios Organizacionales.
\end{abstract}

Palabras clave: Comprensión empática. Estética. Estudios organizacionales.

Artigo submetido em 15 de agosto de 2015 e aceito para publicação em 13 de novembro 2017.

DOI: http://dx.doi.org/10.1590/1679-395155010 


\section{INTRODUÇÃO}

Compreender as experiências que vivenciamos durante a realização de uma pesquisa exige métodos que favoreçam a apreensão do sentimento em seu ser-em-uso por parte do pesquisador. Esse entendimento nem sempre é possível pelos caminhos lógico-racionais preconizados pelos métodos positivistas de investigação.

Weber $(1979,2012)$ enfatizou as fronteiras indistintas entre os processos resultantes das ações racionais e das ações intuitivas, apesar de atribuir um papel vital à racionalidade intencional. Em seus primórdios, a sociologia weberiana, apesar de ter destacado a explicação causal da ação social, evidenciou, além do caráter lógico racional, o papel da compreensão empática (verstehende Soziologie) para as Ciências Sociais, envolvendo as dimensões empática, artística e emocional da compreensão (verstehen) (WEBER, 2012; RINGER, 2004). Nesse sentido, ao enfatizar a compreensão empática se pretende focalizar a questão metodológica na qual o pesquisador se coloca no lugar do outro cuja ação deseja investigar (STRATI, 2007).

Essa discussão se refere aos ensaios metodológicos de Weber $(1979,2012)$ que ficaram conhecidos pela proposta de unificação das duas linhas analíticas "interpretativa" e "explicativa", sendo a primeira dominante na abordagem weberiana. Nos termos dessa tradição, a principal tarefa do historiador ou teórico da cultura é a compreensão (verstehen) "hermenêutica" ou interpretativa (deuten) dos "significados" humanos (RINGER, 2004).

Max Weber retomou e depois abandonou o conceito idealista de Bildung, com o objetivo de elucidar esse modelo de interpretação baseado no princípio de empatia que postulava que os historiadores se colocassem no lugar dos agentes históricos que procuravam compreender. Os atos históricos devem ser compreendidos com base nas intenções e crenças dos agentes e não explicados a partir de instâncias causais. O significado da Bildung weberiano era entendido em termos metafóricos e não como um processo de reprodução de empatia que não pode ser validado (RINGER, 2004).

Nesse sentido, Max Weber já anunciava, muito tempo antes da crise representacional das ciências, perspectivas e posicionamentos que, mais tarde, mudariam as formas de produção do conhecimento. Burrell e Morgan (1979) atribuíram a Weber, por meio do método da compreensão, um papel decisivo de regulação, buscando o equilíbrio entre a importância dos significados subjetivos e suas limitações. Segundo esses autores, Weber estabeleceu um caminho por meio do qual foi possível construir pontes entre o idealismo e o positivismo. Isso evidencia a importância da sociologia compreensiva de Weber para as Ciências Sociais e, em particular, para os Estudos Organizacionais.

O método da compreensão tem sido objeto de discussão e debate ao longo do tempo. Alguns autores (p. ex., ABEL, 1948; GRIMM, 2012; MUNCH, 1957; WIERZBICKA, 2012) esboçaram posicionamentos em relação à teoria da compreensão. Por outro lado, o método da compreensão empática parece ter tido seu significado esquecido (RINGER, 2004). Realizamos um levantamento nas principais bases de dados e nos periódicos abrigados no portal Periódicos Capes utilizando o termo "compreensão empática" aliado a outros como "administração" e "organização", tanto em português como em inglês, no período de outubro de 2013 a janeiro de 2015. Com base nesse levantamento, verificamos que é escassa a produção acadêmica que percorre o caminho da compreensão empática, especificamente na área de Administração no Brasil. Embora alguns textos (p. ex., CÂMARA, 2010; MONTE e MESQUITA, 2013) mencionem a sociologia compreensiva, são quase inexistentes os estudos que resgatam o método weberiano da compreensão empática (p. ex., IPIRANGA, LOPES e SOUZA, 2016; LOPES, SOUZA e IPIRANGA, 2014; LOPES, 2014).

Dada a incipiência de escritos e estudos no Brasil, buscamos neste artigo resgatar a compreensão empática como método, bem como seu uso nas pesquisas em Estudos Organizacionais. Optamos pela abordagem da estética nas organizações como pano de fundo das discussões, por ter sido esse o caminho já percorrido na literatura internacional sobre estética por Strati (1992, 1996, 2007, 2010).

Ao colocarmos em discussão esse resgate metodológico, inicialmente apresentamos as bases históricas e epistemológicas que apoiaram a compreensão empática weberiana. Em seguida articulamos brevemente a perspectiva estética da vida organizacional e proporcionamos um panorama reflexivo das publicações sobre a temática. Em seguida, apresentamos um caminho a ser trilhado pelos estudos que almejam utilizar a compreensão empática como esteio teórico-metodológico para o estudo da estética nas organizações. Na terceira sessão, discutimos as possíveis contribuições que a compreensão empática pode proporcionar às pesquisas no âmbito dos Estudos Organizacionais. Com isso, esperamos estimular e ampliar a reflexão sobre a opção metodológica da compreensão empática. 


\section{A COMPREENSÃO DE MAX WEBER E O RESGATE DA EMPATIA}

Para melhor entendimento da compreensão empática, mostra-se indispensável um retorno às suas raízes epistemológicas. Podemos encontrar grande parte dessa base na sociologia compreensiva delineada por Max Weber (MATTOS, 2011).

Ringer (2004) coloca que um dos grandes feitos de Max Weber foi a integração de duas perspectivas divergentes que vinham dividindo teóricos das ciências históricas, sociais e culturais desde o século XIX. Essa discussão se refere aos ensaios metodológicos de Max Weber $(1979,2012)$ que ficaram conhecidos por essa proposta de unificação entre as duas linhas analíticas "interpretativa" e "explicativa", sendo a primeira dominante na abordagem weberiana. Nos termos dessa tradição, a principal tarefa do historiador ou teórico da cultura é a compreensão (verstehen) "hermenêutica" ou interpretativa dos "significados" humanos (RINGER, 2004).

Nesse contexto, Weber retomou o conceito idealista de Bildung, com o objetivo de elucidar esse modelo de interpretação baseado no princípio de empatia, que postulava que os historiadores se colocassem no lugar dos agentes históricos que procuravam compreender. Os atos históricos devem ser compreendidos com base nas intenções e crenças dos agentes e não explicados a partir de instâncias causais (RINGER, 2004).

O Bildung refletia a questão da educação advinda do século XVIII cunhada pelo idealismo Alemão. Bildung configura um conceito que gera movimento (bewegungsbegriffe), que, ao mesmo tempo, constitui parte de uma conjuntura sociocultural e forças de transformação no desenvolvimento da mesma (PEUKERT, 2002). Por outro lado, e segundo Ringer (2004), o significado da Bildung weberiano poderia ser entendido em termos metafóricos e não como um processo de reprodução de empatia, que não pode ser validado.

Weber $(2012$, p. 4) era particularmente cauteloso quanto ao papel da empatia "não é preciso ser César para compreender César". A possibilidade de "reviver" uma ação é importante para a evidência da compreensão, mas não é condição absoluta para a compreensão do sentido. Assim, a compreensão de uma relação de significados deve ser aferida com os métodos usuais da análise causal (WEBER, 2012). E, nesses termos, a compreensão (verstehen) foi definida por Weber (2008) como a interpretação do significado ou complexo de significados efetivamente intencionais em um caso particular.

Segundo Ringer (2004), ao mesmo tempo que sempre considerou a interpretação um elemento de análise causal, ressaltando a necessidade de uma "explicação interpretativa", Weber também sempre enfatizou o papel da interpretação (deuten) e da compreensão interpretativa (verstehen) para caracterizar seu programa metodológico. Apesar de reconhecer o papel da psicologia do senso comum naquilo que costumava chamar de compreensão empática, Weber resistia e raramente se referiu a compreensão empática (verstehende Soziologie).

Contudo, Weber $(1979,2012)$ também enfatizou as fronteiras indistintas entre os processos resultantes das ações racionais e das ações intuitivas, apesar de atribuir um papel vital à racionalidade intencional. Ringer (2004) relembra que entre os anos 1917 e 1919 e baseado nas interpretações de Wilhelm Dilthey acerca do caráter não construído e integral da experiência pré-teórica vivida, Weber também colocou em discussão a busca do conhecimento intuitivo, da inspiração e da experiência vital (erleben) no contexto das pesquisas e dos negócios. Para o sociólogo, a interpretação baseada no modelo da racionalidade é um instrumento estratégico e não um fim último da sociologia. $E$, nesse sentido, a sociologia não é inerentemente racionalista, sendo esse racionalismo exclusivamente heurístico (RINGER, 2004).

A partir da abordagem do "tipo ideal", a ênfase na teoria da interpretação weberiana recai no papel tático atribuído aos desvios interpretativos observados em relação à racionalidade intencional. O tipo ideal é deliberadamente construído para projetar o curso da ação que se seguiria da racionalidade intencional, estabelecendo a divergência entre ela e a efetiva progressão das ações, possibilitando a atribuição causal do desvio às irracionalidades que a determinam. A abordagem do tipo ideal tem três funções: primeiro indica as etapas do processo de interpretação. Em segundo, possibilita aos intérpretes articular as relações de significados que de acordo com eles estariam envolvidas nas ações. E, por último, enfatiza o papel ativo do investigador na interpretação das ações, com efeitos relacionados, mesmo que remotamente, ao ideal alemão do Bildung (RINGER, 2004).

Para Burrell e Morgan (1979) o método da compreensão assimilado ao esquema de análise do tipo ideal possibilita a ordenação e explicação dos significados da ação humana. Para esses autores, Weber pode ser visto como um "sociólogo da regulação", pois suas ideias contribuíram para a fundação do paradigma interpretativista, reconciliando as potenciais divergências entre o idealismo e o positivismo (BURELL e MORGAN, 1979). 
Maffesoli (1988) coaduna quando afirma que a atitude compreensiva de Weber não se satisfaz com o causalismo excessivo em relação ao objeto, do mesmo modo que rejeita um intuicionismo sumário. E, nesse sentido, o projeto compreensivo pode figurar como um divisor de águas capaz de unir, ainda que com risco, as experiências e situações que constituem a polidimensionalidade do vivido (MAFFESOLI, 1988).

O mundo vivido, a simpatia social (SCHELER, 1986), ou a empatia, traduzem, de modo mais ou menos intuitivo, a experiência vivida coletivamente. Nesse sentido, o resgate da empatia e do senso comum é preconizado por Maffesoli $(1988$, p. 23) ao se referir ao movimento pendular entre o "farejador social" atento ao instituinte, ao subterrâneo, e as taxinomias que classificam as formas ou as situações instituídas e oficiais. O tripé constituído pela experiência, o coletivo e vivido pode ter apreciáveis consequências para a renovação metodológica. E, nesse contexto, Maffesoli (1988, p. 33) sugere uma "sociologia aberta" apta a integrar saberes especializados em um conhecimento plural.

Embora alguns autores (p. ex., ABEL, 1948) sejam contrários à compreensão empática, enquanto método válido para a pesquisa, outros a defendem, especialmente no que diz respeito à necessidade de compartilhamento de conceitos, o que favorece o entendimento do outro (WIERZBICKA, 2012) e uma epistemologia superior ao próprio conhecimento (GRIMM, 2012). Sobretudo no contexto internacional, a compreensão empática vem sendo retomada por alguns autores, entre eles Strati (1992, 2007), como uma das bases para o estudo de temáticas emergentes como, por exemplo, a estética na vida das organizações. No entanto, no Brasil a compreensão empática ainda é pouco explorada, especialmente no campo do estudo das organizações (p. ex., IPIRANGA, LOPES e SOUZA, 2016; LOPES, SOUZA e IPIRANGA, 2014; LOPES, 2014). Por isso, retemos como oportuno propor esse debate sobre a opção teórico-metodológica da compreensão empática, tendo por pano de fundo a abordagem da estética organizacional.

\section{A ABORDAGEM DA ESTÉTICA ORGANIZACIONAL}

A estética constitui uma teoria filosófica que foi inicialmente abordada por Platão e Aristóteles na Grécia Antiga, a partir das discussões desses filósofos sobre a noção de beleza. Para Platão (1993), a estética era uma noção oposta à noética. Esta última era entendida como o conhecimento intelectual ou teórico. Nesse sentido, a lógica compreendia o estudo do conhecimento intelectual, enquanto a estética dava conta do estudo sensorial, apreendido por meio dos sentidos humanos. Ainda para Platão (1993), o termo estética se referia a uma excitação da alma e do corpo, que conduzia a um conhecimento sensível.

Para Aristóteles (1984), a estética era uma das cinco faculdades da alma, aquela que permitia aos sujeitos formarem uma imagem mental dos objetos do mundo. Essa imagem, mais tarde, seria convertida em conhecimento abstrato pelas faculdades mais elevadas do espírito.

Em 1790, Kant (2012) atribuiu uma nova conotação à forma e ao conteúdo da estética, na qual a noção de existência de uma beleza absoluta e paradigmática será substituída pela prioridade do juízo do gosto, e o belo (kalós) é considerado uma finalidade sem fim. Para Kant (2012), a estética trata do estudo da experiência aprendida enquanto intuição, sentimentos, emoções, produzindo um efeito de prazer, de caráter desinteressado, que o autor denomina experiência estética. O belo (kalós) é a condição de objeto da experiência estética.

Contudo, foi em 1750, com Baumgarten (1993), que a estética foi conceituada como a teoria do saber sensível, problematizando-a como ciência. Baumgarten (1993) afirmou que era possível assimilar a estética como um domínio da sensibilidade relacionado à percepção, aos sentimentos e à imaginação. Para o autor, a estética consistia na perfeição do conhecimento sensível. Assim, a beleza e seu reflexo nas artes representava uma espécie de conhecimento ligado à sensibilidade do ser humano, oposto ao conhecimento racional, responsável pela clareza e pela verdade (BAUMGARTEN, 1993).

Segundo Strati (1992), no campo organizacional a estética se refere a uma forma de conhecimento humano e, especificamente, ao conhecimento proporcionado pelas faculdades perceptivas da audição, da visão, do tato, do olfato e do paladar e do pensamento, pela capacidade de formular um juízo estético (STRATI, 1996, 2000, 2007; TAYLOR e HANSEN, 2005).

Esse juízo “permite avaliar se alguma coisa é agradável ou não, se corresponde ao nosso gosto ou não, se nos 'envolve' ou nos deixa indiferentes, ou mesmo nos repugna" (STRATI, 2007, p. 11). A organização, ou as atividades realizadas a partir das interações dos atores organizacionais, pode ser considerada bela, feia, engraçada, profana ou mesmo sagrada. Esse julgamento 
estético baseia a ação social que constrói a vida organizacional, com base nas negociações de significados da interação organizacional. Assim, a estética irrompe como uma parte inegável das organizações, pois as experiências estéticas estão por toda parte e podem ser vividas por qualquer pessoa dentro desse contexto (OTTENSMEYER, 1996; STRATI, 1996).

Dessa forma, os juízos estéticos, enquanto avaliação subjetiva da organização, podem ser negociados, interpretados e alterados pelos sujeitos organizacionais. Nesse sentido, o juízo estético fornece conhecimento sobre como o indivíduo representa a organização para si e não necessariamente como ela é de fato (KANT, 2012; STRATI, 1992, 2007). Assim, um conjunto de experiências e juízos colaboram para o organizar estético das organizações, enfatizando os sentimentos e as sensações existentes no cotidiano, bem como o engajamento dos sujeitos no dia a dia da organização.

A abordagem estética da vida organizacional emergiu nos anos 1970 e 80. Nessa época, as organizações eram concebidas no plano racional a partir de um pensamento puramente instrumental, sendo sua dimensão sensível relegada (GAGLIARDI, 2009; STRATI, 2007). Essa visão, no entanto, foi paulatinamente alterada com o crescimento de abordagens que privilegiavam outras dimensões da vida organizacional que não a dimensão lógico-racional. Surgiram, então, abordagens que se preocupavam em entender outras dimensões organizacionais como, por exemplo, a sensível.

O entendimento das questões que envolviam dimensões imateriais, como emoções e sentimentos, ancorava-se em pressupostos metodológicos que priorizavam o entendimento da ação dos sujeitos. Nesse âmbito, voltamo-nos para a compreensão weberiana e, como anteriormente colocado, Weber (2012) também enfatizou as fronteiras indistintas entre os processos resultantes das ações racionais e das ações intuitivas, apesar de atribuir um papel vital à racionalidade intencional. Por outro lado, e tendo por base as interpretações de Wilhelm Dilthey acerca do caráter não construído e integral da experiência pré-teórica vivida, Weber também colocou em discussão a busca do conhecimento intuitivo, da inspiração e da experiência vital (erleben) no contexto das pesquisas e dos negócios. Para o sociólogo, a interpretação baseada no modelo da racionalidade é um instrumento estratégico e não um fim último da sociologia. E, nesse sentido, a sociologia não é inerentemente racionalista, sendo esse racionalismo exclusivamente heurístico (RINGER, 2004).

Essas reflexões foram a base para a crise de representação das ciências, pela qual também passou o campo dos Estudos Organizacionais no movimento da perspectiva positivista-funcionalista para a perspectiva crítico-interpretativa (TAYLOR e HANSEN, 2005). Nesse contexto, foram esboçadas críticas ao paradigma estrutural, especialmente no que diz respeito às limitações que pouco auxiliam na compreensão das organizações e à visão reificada das organizações, que ignorava a vontade dos sujeitos (STRATI, 2007).

Esse debate abriu caminho, entre outras abordagens, para o uso da estética como lente para investigar as organizações. Desse modo, a incorporação da teoria estética aos Estudos Organizacionais é relativamente recente. Seu desenvolvimento ocorreu a partir de uma série de acontecimentos, entre eventos e edições especiais de publicações, onde os estudos começavam a iluminar diferentes faces das organizações (Quadro 1).

\section{Quadro 1}

\section{Cronologia de acontecimentos relevantes para a abordagem da estética nas organizações}

\begin{tabular}{ccl}
\hline ANO & ACONTECIMENTO & IMPORTÂNCIA \\
\hline 1985 & $\begin{array}{l}\text { A temática sobre imagem empresarial trouxe trabalhos que versavam sobre questões como } \\
\text { a identidade organizacional transmitida graficamente pela organização (COSTA, 1986), } \\
\text { Organizational Studies (SCOS), } \\
\text { organizada por Vicent Degòt } \\
\text { transmitida a partir das imagens que circulam no interior (BOLOGNINI, 1986) e exterior } \\
\text { (SCHNEIDER e POWLEY, 1985) da organização e que representam importantes eventos } \\
\text { organizacionais no que diz respeito à identidade e identificação com a organização e sobre a } \\
\text { desconstrução do discurso organizacional oficial (GRAFTON-SMALL e LINSTEAD, 1985). }\end{array}$ \\
\hline $\begin{array}{c}\text { Edição especial da revista } \\
\text { Dragon (v. 2, n. 3), editada por } \\
\text { Pierre-Jean Benghozi }\end{array}$ & $\begin{array}{l}\text { Compilação das pesquisas mais relevantes apresentadas na SCOS de 1985. } \\
\text { III Standing Conference on } \\
\text { Organizational Studies (SCOS), } \\
\text { em Milão, Itália }\end{array}$ & $\begin{array}{l}\text { Com a temática "The Symbolics of Coporate Artifacts", foram apresentadas pesquisas } \\
\text { organização, a gestão de organizações que realizam atividades ligadas à arte, bem como } \\
\text { as práticas cotidianas que se relacionam com a arte. }\end{array}$ \\
\hline
\end{tabular}


Continuação

\begin{tabular}{|c|c|c|}
\hline ANO & ACONTECIMENTO & IMPORTÂNCIA \\
\hline 1987 & $\begin{array}{c}\text { Edição da revista Dragon (v. 2, } \\
\text { n. 4) editada por Pierre-Jean } \\
\text { Benghozi }\end{array}$ & $\begin{array}{l}\text { Reuniu alguns trabalhos que apresentaram diferentes abordagens do estudo da } \\
\text { estética nas organizações, analisando aspectos que não estavam relacionados apenas à } \\
\text { estrutura física. Destacaram-se os estudos que: } \\
\text { - Compararam as práticas de gestão às produções artísticas, cuja qualidade pode ser } \\
\text { julgada esteticamente, pois utilizar apenas a lente dos negócios para examinar tais } \\
\text { práticas não permite enxergar seu significado completo (DEGÒT, 1987); } \\
\text { - } \quad \text { legaram que as corporações podem ser consideradas bonitas ou elegantes tanto } \\
\text { pelas pessoas internas como externas à organização, bem como são um adequado } \\
\text { objeto de estudo e avaliação em termos estéticos (RAMIREZ, 1987a); } \\
\text { - Enfatizaram o fato de que os teóricos são muito mais inclinados a devotar sua } \\
\text { atenção para a imagem corporativa e o impacto nas pessoas em torno dela do que } \\
\text { para a própria organização (RAMIREZ, 1987b); } \\
\text { Exploraram a forma como as decisões sobre a estética das cerimônias ilumina a } \\
\text { construção social da comunicação organizacional (RUSTED, 1987). }\end{array}$ \\
\hline
\end{tabular}

Lançamento da coletânea

\section{Symbols and artifacts: views}

1990 of the corporate landscape,

organizada por Pasquale

Gagliardi

Edição especial do periódico

Academy of Management

Review (v. 17, n. 3), dedicada às abordagens emergentes nos

1992

Estudos Organizacionais. Os editores na ocasião eram Linda Smircich; Marta Calás e Gareth Morgan

Edição especial da revista

Organization (v. 3, n. 2), dedicada à temática da estética

Publicação do Handbook of organizational studies (v. 2),

1996 com um capítulo dedicado aos artefatos organizacionais, elaborado por Pasquale Gagliardi

Publicação da obra Organization 1999
Trouxe, além de outros trabalhos, as pesquisas publicadas tanto na SCOS de 1985 como na Dragon (v. 2, n. 3)
Nessa edição foi publicado o trabalho de Antônio Strati, membro fundador da SCOS, que abordava a estética como o caminho para a compreensão da vida organizacional. No estudo, Strati (1992) realizou uma discussão epistemológica onde apresentou a estética como uma forma legítima para compreender as organizações por meio de uma abordagem que não enquadre "a estética dentro das várias caixas onde a vida organizacional é estudada", pois o conhecimento gerado pelo exame da experiência estética é rico e plausível.

Dentre os trabalhos publicados destacam-se aqueles que:

- Compreenderam a estética como uma importante forma de conhecimento organizacional (STRATI, 1996);

- Salientaram sua pertinência para o estudo das organizações por fornecer uma visão a respeito da beleza - elemento constitutivo da vida organizacional (WHITE, 1996);

- Compreenderam a forma - arquitetura, design, entre outros - da organização como um artefato que oferece aos atores organizacionais uma experiência sensorial direta (RAMIREZ, 1996).

Nesse capítulo, a discussão sobre os artefatos organizacionais e a forma como são percebidos pelos sentidos foi levantada, afirmando que as organizações estão repletas de conhecimento sensorial (GAGLIARDI, 2009).

O livro promoveu o que pode ser chamado de virada estética, compreendendo esta como uma lente em potencial para entender as organizações. No Brasil, a obra foi traduzida e publicada em 2007. 
ANO ACONTECIMENTO

Edição especial da revista

2002 Human Relations (v. 55, n. 7)

\section{IMPORTÂNCIA}

A edição foi dedicada à exploração da vida organizacional a partir de abordages stéticas, tanto em investigações teóricas como empíricas. Tal feito preconiza a adoção de um estilo dialógico que permita várias interpretações que não incorram nas dicotomias teóricas como, por exemplo, mente e corpo, belo e feio, entre outros. Destacam-se nessa edição os trabalhos de:

- Martin (2002), que descortinou a noção de "espírito de lugar" ao explorar como estava organizada a experiência estética em um abrigo para pessoas idosas no Reino Unido, por meio do exame das sensações dos residentes;

- Pelzer (2002), que explorou a categoria do nojo, interpretando-o como uma forma de conhecimento. De acordo com o autor, seu trabalho foi capaz de demonstrar o poder da teoria estética para a obtenção do conhecimento nas organizações;

- Taylor (2002), que investigou a incapacidade de expressar a experiência estética. 0 autor chamou isso de mudez estética e inferiu que suas causas podem ser a ameaças à harmonia, eficiência e imagens de poder e eficácia existentes na organização.

O livro promoveu o que pode ser chamado de virada estética, compreendendo esta
Publicação da obra

1999

Organization and aesthetics, de Antônio Strati

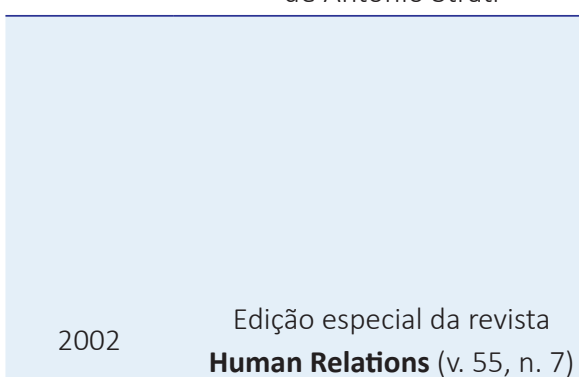

2007

Lançamento do projeto Aesthesis como uma lente em potencial para entender as organizações. No Brasil, a obra foi traduzida e publicada em 2007.

A edição foi dedicada à exploração da vida organizacional a partir de abordagens estéticas, tanto em investigações teóricas como empíricas. Tal feito preconiza a adoção de um estilo dialógico que permita várias interpretações que não incorram nas dicotomias teóricas como, por exemplo, mente e corpo, belo e feio, entre outros. Destacam-se nessa edição os trabalhos de:

- Martin (2002), que descortinou a noção de "espírito de lugar" ao explorar como estava organizada a experiência estética em um abrigo para pessoas idosas no Reino Unido, por meio do exame das sensações dos residentes;

- Pelzer (2002), que explorou a categoria do nojo, interpretando-o como uma forma de conhecimento. De acordo com o autor seu trabalho foi capaz de demonstrar o poder da teoria estética para a obtenção do conhecimento nas organizações;

- Taylor (2002), que investigou a incapacidade de expressar a experiência estética. 0 autor chamou isso de mudez estética e inferiu que suas causas podem ser a ameaças à harmonia, eficiência e imagens de poder e eficácia existentes na organização.

The Aesthesis Project foi lançado em janeiro de 2007 como um projeto de pesquisa para investigar a arte e a estética na gestão e nos contextos organizacionais, trazendo artistas, designers, consultores de negócios e professores de gestão. Isso estendeu a estética organizacional para um campo interdisciplinar.

\begin{tabular}{|c|c|c|}
\hline 2007 & $\begin{array}{l}\text { Lançamento da revista Aesthesis, } \\
\text { International Journal of Art and } \\
\text { Aesthetic in Management and } \\
\text { Organizational Life }\end{array}$ & $\begin{array}{l}\text { Publicada em } 6 \text { volumes, a revista foi parte do projeto Aesthesis, no entanto, não era } \\
\text { uma publicação rotineira da academia. Nos } 6 \text { volumes publicados, o periódico trouxe } \\
\text { uma série de questões relativas à abordagem estética. }\end{array}$ \\
\hline 2012 & $\begin{array}{l}\text { Lançamento do periódico } \\
\text { Organizational Aesthetics, } \\
\text { atualmente editado por Steven } \\
\text { S. Taylor }\end{array}$ & $\begin{array}{l}\text { A revista do projeto Aesthesis foi continuada como o periódico Organizational Aesthesis. A } \\
\text { revista almeja chegar a lugares até agora não explorados pela literatura, a partir de tópicos } \\
\text { como o uso de métodos baseados em arte nas organizações, a divulgação de fenômenos } \\
\text { estéticos nas organizações e a arte que existe subjacente ou na própria organização. }\end{array}$ \\
\hline 2013 & $\begin{array}{l}\text { Lançamento do livro } \\
\text { Experiencing organizations: new } \\
\text { aesthetic perspectives, editado } \\
\text { por Jonathan Vickery e lan King }\end{array}$ & $\begin{array}{l}\text { O lançamento desse livro foi o resultado mais recente do projeto Aesthesis e foi } \\
\text { lançado na Copenhagen Business School, em } 3 \text { de maio de } 2013 .\end{array}$ \\
\hline
\end{tabular}

Fonte: Elaborado pelos autores. 
Atualmente, as pesquisas sobre estética nas organizações se dedicam a diferentes debates, como o entrelaçamento entre as noções de estética e a criação de estratégia (p. ex., FILIPPI e TANNERY, 2009); a discussão a respeito das abordagens utilizadas para o estudo da estética, dando atenção especial aos temas de emancipação das pessoas no trabalho, os estilos e as práticas organizacionais (p. ex., STRATI, 2010) e sobre como os artefatos estéticos são implantados para a criação e/ou controle de indivíduos no contexto organizacional (p. ex., SORENSEN, 2010).

O trabalho de Sorensen (2010) chamou a atenção por se propor a examinar a forma como a produção artística do pintor Caravaggio, intitulada A Conversão de São Paulo (1600/1601), transmite imagens de empreendedorismo e dos processos organizacionais, contribuindo para o desenvolvimento de uma abordagem crítica à estética organizacional.

Outras investigações discutem a elaboração de um modelo mais abrangente do papel da estética organizacional na regulação da identidade e no rompimento com padrões culturais (p. ex., WASSERMAN e FRENKEL, 2011); o uso do conhecimento estético como elemento de ligação entre a gestão e o design (p. ex., STEPHENS e BOLAND, 2011); a relação entre a ética e a estética, por meio da análise da noção de beau geste no âmbito da liderança (p. ex., BOUILLOUD e DESLANDES, 2013). As pesquisas sobre estética (p. ex., KURONEN, 2012) também se dedicaram a entender como a beleza molda as percepções dos indivíduos sobre os processos organizacionais.

Alguns estudos ainda discorreram sobre o potencial das formas artísticas, como o teatro, para a pesquisa em estética organizacional (p. ex., BIHELMISSAL, 2012); outros utilizaram a abordagem artístico-estética para ampliar o alcance da estética organizacional na experiência de sala de aula de um curso de pós-graduação (p. ex., MACK, 2013). A pesquisa de Mack (2013), a partir da revelação de que o próprio processo criativo é carregado de valor estético, contribuiu tanto para o conhecimento artístico-estético do grupo como para ampliar o uso da abordagem da estética, nesse caso, entrelaçando-a com as práticas de educação em Administração. No Brasil, a pesquisa sobre a temática começou a ser desenvolvida a partir do ano 2000 quando vários trabalhos, teóricos e empíricos, foram publicados com investigações a respeito das possíveis contribuições da estética, enquanto ciência filosófica para a análise das organizações (p. ex., CSILLAG, 2003; LEAL, 2000, 2002, 2007; LEAL e ROCHA, 2008; WOOD e CSILLAG, 2001).

Já no campo da pesquisa empírica, a discussão avançou para uma aproximação entre o conhecimento tácito e a estética a partir do estudo com proprietários de pequenas empresas da região metropolitana de Belo Horizonte (TAVARES e KILIMNIK, 2007). Esse estudo ressaltou as semelhanças entre as duas formas de conhecimento, especialmente o caráter não verbalizável, a noção de experiência e pessoalidade.

Outros estudos empíricos ampliaram as articulações até então realizadas e progrediram para o debate da relação da aprendizagem com as questões da prática de trabalhadores da construção civil no município de Santa Maria-RS, a partir de um estudo de caso qualitativo (SCHIAVO, 2010) e de profissionais que atuam em uma revenda de móveis panejados, em Porto Alegre, com base em uma pesquisa etnográfica (OLIVEIRA, 2012).

Recentemente, algumas pesquisas utilizaram os princípios metodológicos da compreensão empática para descrever a experiência estética imbuída nas práticas culinárias e sua relação com a gestão de um pequeno restaurante (IPIRANGA, LOPES e SOUZA, 2016), bem como as categorias estéticas presentes em uma organização gastronômica, desvelando a forma como elas influenciam na organização do restaurante (LOPES, SOUZA e IPIRANGA, 2014). Já Lopes (2014) se dedicou a investigar como ocorre a experiência estética imbuída nas práticas culinárias dos pequenos restaurantes circunscritos no polo gastronômico de um mercado popular.

A articulação alcançada pelo campo no decorrer do tempo mostra como a estética pode ser utilizada para entender o cotidiano organizacional em suas mais diversas faces, promovendo um conhecimento até então não revelado pela racionalidade instrumental. Muito embora não seja o escopo desta pesquisa promover uma ampla e profunda revisão da literatura já publicada sobre estética, os estudos apresentados até o momento mostram que a temática conseguiu se firmar como corrente de estudos com sua própria tradição de pesquisa, bem como estabelecer suas controvérsias tanto teóricas como metodológicas (STRATI, 2007).

\section{A PESQUISA BASEADA NA COMPREENSÃo EMPÁTICA: CONSIDERAÇÕES A PARTIR DA ESTÉTICA ORGANIZACIONAL}

$\mathrm{Na}$ abordagem estética, a questão metodológica acaba por se tornar um dos fundamentos da estética moderna (STRATI, 2007). O autor igualmente salienta que a escolha de um paradigma para a condução de pesquisas organizacionais também está ancorada em considerações estéticas. Desse modo, para compreendermos os motivos afetivos, artísticos, sensíveis e ou emocionais que guiam a ação de alguém, é necessário o emprego da compreensão empática, cuja definição refinada por Strati (2007, p. 80) "consiste em se imaginar no lugar de uma pessoa cujos propósitos, motivos e sentidos se deseja explicar". 
Nesse sentido, razões, significações e emoções são relacionadas à ação dos sujeitos, em determinado contexto, para desvendar os motivos de sua ação (STRATI, 2007). Isso sugere a opção epistemológica que dá prioridade ao entendimento estético da vida organizacional, pois é o conhecimento sensível que evidencia as diferenças entre as Ciências Naturais e as Ciências Sociais, bem como suas opções teóricas e metodológicas.

Assim, o uso da compreensão empática como base teórica e metodológica de sustentação da pesquisa de cunho estético enfatiza que essa é "a opção epistemológica que dá prioridade à compreensão estética e a consciência do sensível nas organizações também se funda em considerações estéticas" (STRATI, 2007, p. 83). Além disso, o método empático possibilita ao pesquisador o reconhecimento de humores, pensamentos, e sentimentos estéticos intimamente ligados à ação dos atores organizacionais e, nesse sentido, o pathos com que um evento ou uma ação é enfatizado(a) pelos informantes consiste "no que diz e como diz, este não só fornece ao pesquisador informações sobre processos, como também comunica uma emoção, uma sensação, um sentimento" (STRATI, 2007, p. 272).

A ênfase, então, recai sobre o compartilhamento entre sujeitos e o pesquisador da sensação de prazer, alegria ou desprazer causada por algum evento organizacional, proporcionando o "sinal distintivo" (STRATI, 2007, p. 272) para orientar a investigação. O sentimento caracteriza o estudo estético da vida organizacional cotidiana, por ser a qualidade expressiva intrínseca aos fenômenos estéticos, constituindo o "modo [das] coisas, as situações e as formas se oferecerem" (STRATI, 2007, p. 273).

Nesse entendimento, Strati (2007), apoiado na ideia de compreensão empática weberiana, delineou métodos próprios de investigação de organizações a partir de uma abordagem estética. Nesse sentido, o autor propõe um roteiro metodológico a ser seguido, a princípio, por pesquisas baseadas em uma abordagem estética. O método empático preconiza inicialmente a imersão do pesquisador no contexto a ser estudado, seguido pela ativação das suas faculdades sensoriais, em prol de experimentar por meio de sentimentos e emoções o contexto organizacional. Ou seja, devemos estar com nossos cinco sentidos plenamente atentos às sensações que posteriormente se transformarão em experiência vivida.

A opção metodológica da compreensão empática rejeita o distanciamento do cientista do fenômeno que almeja investigar (WEBER, 2008). Essa identificação entre pesquisador e pesquisado também acarreta um envolvimento em experiências pessoais, necessário para que se possa compreender as causas que originam as ações das pessoas.

Subjacente à ativação das faculdades sensoriais, propõem-se os seguintes princípios que atuam na construção do corpus empírico das pesquisas sobre a estética organizacional desenvolvidas segundo o método empático: a auto-observação, o uso da intuição, da analogia e o reviver da experiência na imaginação (STRATI, 2007). Na auto-observação, "o pesquisador se observa enquanto se põe no lugar de uma outra pessoa" (STRATI, 2007, p. 107). Ao examinar as sensações provocadas pela ação, seus motivos e os julgamentos que podem ser feitos sobre ela, o investigador constata e descreve os humores que Ihe foram provocados, as emoções que ele mesmo sentiu e os pensamentos que the vieram à mente de forma secundária.

Essas informações mostram como o pesquisador se interpreta no decorrer da ação organizacional. O procedimento da auto-observação é caracterizado como analítico por ter como objetivo captar as diferentes variações que fazem daquela ação particular e distinta das demais. Assim, a auto-observação vai de encontro ao cerne das questões colocadas por Weber. No entanto, frisamos aqui, ratificando que não se trata apenas de um reviver empático, mas sim uma busca, por meio de si, dos fins das ações e dos meios que os sujeitos detinham para alcançar os fins desejados (PAIVA, 1997). Entendemos, assim como Strati (2007), que é por meio do princípio da auto-observação que o corpus empírico, segundo a compreensão empática, é construído, visando ao entendimento dos fins e meios que edificam as ações dos sujeitos.

Além disso, o autor pontua a intuição como um instrumento subjacente, enfatizando que sem ele "é impossível obter conhecimento empático da ação intencional do ator organizacional" (STRATI, 2007, p. 108). Para assumirmos o papel de outro é necessário que estejamos com esse processo ativo. Seu uso pode ser evidenciado nos momentos em que utilizamos os sinais que nos demonstram humores, impressões e avaliações relativas à(s) ação(ões) do(s) sujeito(s) que tentamos compreender.

Assim como a intuição esteia uma pesquisa baseada na metodologia compreensiva, a analogia também "possibilita que o pesquisador estabeleça uma relação dinâmica como que pensa e sente o ator organizacional e, assim, com a ação intencional em exame" (STRATI, 2007, p. 108). Destarte, a analogia nos permite presumir a existência de sinais que manifestam os estados de espírito do sujeito. É por meio dela que podemos imaginar o que esse indivíduo pensa e sente naquele momento, bem como o que ele pode estar prestes a sentir no decorrer da ação organizacional (STRATI, 2007).

No entanto, dentre estas possibilidades de construção do corpus de pesquisa, o autor coloca como mais importante a atividade de reviver a experiência na imaginação. Essa é a principal fonte de informações quando se emprega a compreensão empática para o estudo estético das organizações. O pesquisador, por meio do uso de "suas faculdades intuitivas, emprega 
a analogia, ou confia em uma combinação dos métodos para se pôr no lugar de outrem" (STRATI, 2007, p. 109). Nesse contexto, observamos a nós mesmo de modo a tentar entender os motivos que levam o sujeito a agir de determinada forma e descrevemos aquilo que vemos e sentimos. Pontuamos, contudo, que não se trata apenas de reviver as ações do outro apenas no que tange à nossa subjetividade, mas sim reviver por meio de um trabalho racional, ainda que intuitivo (POKER, 2013).

Assim, ao nos colocarmos no lugar do outro, geramos um conhecimento pré-reflexivo, pois não nos debruçamos sobre representações da realidade dadas por outrem, mas examinamos nossos próprios sentimentos e emoções, como parte do contexto de estudo (FLORES-PEREIRA, 2010). Ao fazermos isso, engendramos informações qualitativas específicas, baseadas no caráter empático do conhecimento (STRATI, 2007).

No momento da construção do corpus empírico, Strati (2007) alerta que é preciso que definamos a maneira como nos colocaremos no lugar do outro, ou seja, apontemos a situação da empatia. Então, podemos nos colocar no lugar de outra pessoa de três maneiras diferentes: a primeira delas é por meio da verificação das hipóteses. Ainda que soe estranho falar de hipóteses em um estudo de caráter qualitativo, Strati (2007, p. 109) justifica o termo afirmando que, ao tentarmos verificar os motivos que levam o sujeito à ação nós podemos nos deparar com muitas combinações, as quais ele denomina "hipótese". Algumas dessas hipóteses serão confirmadas, outras serão rejeitadas. No entanto, o que se evidencia aqui é uma coincidência entre pesquisador e pesquisado. Em outras palavras, quanto maior for essa coincidência mais contundente será a compreensão empática.

A segunda forma de nos colocarmos no lugar do outro é por meio do compartilhamento da experiência. Nesse sentido, é necessário que também tenhamos vivido experiências semelhantes, pois conhecer esteticamente só é possível a partir da elaboração de analogias com experiências já vividas. Strati (2007) destaca, ainda, a observação participante imaginativa, onde nós pesquisadores assumimos a figura do outro em nossa imaginação e podemos reviver suas emoções a fim de descrever a plausibilidade dos elementos que emergem. Isso não somos obrigados a nos colocarmos efetivamente no lugar de todos que participam da ação, tampouco compartilhar o ponto de vista do observado. Aqui vivenciamos, por meio da imaginação, vários pontos de vista, ainda que incompletos e/ou fragmentados.

Construído o corpus empírico, passamos à descrição e interpretação dos elementos emersos do campo. Para que possamos empreender uma análise empática, mostra-se necessário realizar o processo de descrição e interpretação com base no reexame das experiências que vivenciamos em campo. A descrição do conhecimento obtido durante a construção do corpus é capaz de constituir um material relevante para a investigação a partir da (re)construção do conhecimento na imaginação. Esse artesanato de sensações relacionadas a pensamentos compreende um "processo contínuo de revisão, releitura, recompreensão e reargumentação" (STRATI, 2007, p. 112) da experiência vivida na imaginação.

Clarificamos que essa descrição deve considerar as diversas vozes que são ouvidas durante a consecução da pesquisa. Para tanto, devemos nos voltar para a arquitetura de um "texto aberto" (STRATI, 2007, p. 116), enfatizando que a mesma maneira de ver se aplica ao escrever sobre os fenômenos, sem retirar sua principal dimensão. Nesse momento, então, algumas características dominantes do processo de empatia se tornam evidentes. Essas características consistem em uma espécie de estratégia heurística, utilizada a fim de nos relacionarmos com o conhecimento empaticamente obtido (STRATI, 2007).

Neste ponto, destacamos que Weber (2012, p. 4) era especialmente cauteloso quanto ao papel da empatia "não é preciso ser César para compreender César". Assim, a possibilidade de "reviver" uma ação é importante para a evidência da compreensão, mas não é uma condição absoluta para a compreensão do sentido da ação. Por outro lado, Weber (1979, 2012) também enfatizou as fronteiras indistintas entre os processos resultantes das ações racionais e das ações intuitivas. Apesar de atribuir um papel vital à racionalidade intencional, o autor também sublinhou a importância do conhecimento intuitivo, da inspiração e da experiência vital (erleben) no contexto das pesquisas e dos negócios. Para o sociólogo, a sociologia não é inerentemente racionalista, sendo esse racionalismo exclusivamente heurístico (RINGER, 2004).

Quando a cognição predomina no processo descritivo e interpretativo, fica evidente que nós pesquisadores focamos nossa atenção nos estados cognitivos do ator organizacional, ou seja, concentramo-nos em pensamentos, reflexões e conjecturas estabelecidas pelos sujeitos. A prevalência da característica estética está relacionada ao foco do pesquisador nos elementos que não podem ser traduzidos em estados cognitivos sem que sejam drasticamente modificados. A preponderância da emoção fica evidente quando direcionamos nossa atenção aos estados emocionais antes que estes sejam traduzidos em estados cognitivos. Dentre esses estados, exemplifica Strati (2007), estão os sentimentos de gratificação e raiva colocados em ação no contexto organizacional.

Implicitamente, e dentro do arcabouço empático, podemos estudar a estética da vida organizacional à luz de três estilos de pesquisa: arqueológico, lógico-empático e empático-estético (STRATI, 2007, 2010; STRATI e MONTOUX, 2002). Essas abordagens demarcam a forma como as investigações são conduzidas na característica da dimensão estética que é mais focada 
(STRATI, 2010). Seu surgimento data do final dos anos 1980 e início dos anos 1990, no âmbito da linha referente aos estudos sobre cultura e simbolismo organizacionais.

Na abordagem arqueológica, assumimos a posição de um arqueólogo ou historiador da arte. Esse estilo é o mais utilizado nas pesquisas sobre estética da vida organizacional e tem como base a investigação dos fragmentos da vida organizacional gerados pela cultura organizacional. Para tanto, ativamos nossas faculdades perceptivas, bem como nosso juízo estético para explorar as informações fornecidas pelos artefatos como a arquitetura organizacional, locais de trabalho e logotipos e os produtos fabricados pela organização para obter conhecimento estético da vida organizacional (STRATI, 2007, 2010; STRATI e MONTOUX, 2002).

Ao investigarmos as informações obtidas por meio dos sentidos, elas são isoladas, assim como os artefatos organizacionais. Dessa forma, obtemos material para interpretar a cultura organizacional do contexto examinado. Berg (1987) afirma que devemos agir como arqueólogos contemporâneos, em busca de descobrir mais sobre a civilização que estamos estudando a partir da investigação de seus fragmentos.

Na abordagem lógico-empática, tanto apreendemos conhecimento de forma empática como lançamos mão da compreensão lógico-racional para interpretação do corpus. Nesse sentido, investigamos tanto os aspectos materiais como os imateriais da organização. Os estudos que utilizam esse estilo passam por três estágios, segundo Gagliardi (2009): i) observação: ocorre quando abandonamos nossa própria intuição passiva e nos interrogamos sobre as sensações despertadas pelo artefato organizacional e as nomeamos; ii) interpretação: quando interpretamos os achados por meio de nossas emoções e reflexões desse modo, buscamos um equilíbrio entre o conhecimento empático e o distanciamento interpretativo; e iii) e, por fim, na análise: quando abandonamos o conhecimento empático e damos lugar ao rigor lógico-analítico.

Quando nos amparamos na abordagem empático-estética, ativamos nossas faculdades sensoriais e nosso juízo estético na compreensão da organização, a fim de nos imbricarmos e compartilharmos empaticamente as atividades dos atores organizacionais. Por fim, compomos um texto aberto, utilizando metáforas e uma linguagem poética, que descreve e evoca as dinâmicas e os processos organizacionais estudados, habilitando o leitor a conduzir em sua imaginação alguma pequena parte do fenômeno organizacional ilustrado (STRATI, 2007). O rigor desse texto e a arquitetura dos argumentos desenvolvidos refletem nossas preferências estéticas. O Quadro 2 apresenta um resumo dos componentes da compreensão empática aplicados nos estudos das organizações.

\section{Quadro 2}

\section{Componentes da compreensão empática da organização}

\begin{tabular}{|c|c|c|}
\hline \multirow{2}{*}{$\begin{array}{l}\text { Disposição do } \\
\text { pesquisador para } \\
\text { "empatizar" }\end{array}$} & $\begin{array}{l}\text { Identificação com o } \\
\text { outro }\end{array}$ & Aproximação do pesquisador com o ambiente que deseja investigar. \\
\hline & $\begin{array}{l}\text { Ativação dos } \\
\text { sentidos }\end{array}$ & $\begin{array}{l}\text { Busca por uma experiência estética direta, na tentativa de saber o que motiva os } \\
\text { sujeitos. }\end{array}$ \\
\hline \multirow{4}{*}{ Coleta do conhecimento } & Auto-observação & Pesquisador se observa enquanto se coloca no lugar do outro. \\
\hline & Intuição & $\begin{array}{l}\text { É utilizada quando o pesquisador julga que alguns sinais observados denotam } \\
\text { avaliações estéticas feitas pelos atores organizacionais. }\end{array}$ \\
\hline & Analogia & $\begin{array}{l}\text { Permite estabelecer uma relação dinâmica com os pensamentos e sentimentos dos } \\
\text { sujeitos organizacionais. }\end{array}$ \\
\hline & $\begin{array}{c}\text { Reviver a } \\
\text { experiência na } \\
\text { imaginação }\end{array}$ & Pesquisador observa a si e descreve a ação que foi realizada. \\
\hline \multirow{3}{*}{$\begin{array}{l}\text { Definição da situação de } \\
\text { empatia }\end{array}$} & $\begin{array}{l}\text { Verificação da } \\
\text { hipótese }\end{array}$ & O pesquisador verifica quais são os motivos que podem explicar a ação dos sujeitos. \\
\hline & $\begin{array}{l}\text { Compartilhamento } \\
\text { da experiência }\end{array}$ & $\begin{array}{l}\text { Empatia é realizada em analogia com as experiências vividas pelo pesquisador ao } \\
\text { longo da vida. }\end{array}$ \\
\hline & $\begin{array}{l}\text { Observação } \\
\text { participante } \\
\text { imaginativa }\end{array}$ & $\begin{array}{l}\text { A imaginação do pesquisador permite que ele assuma a aparência do outro, sem } \\
\text { efetivamente realizar a ação. }\end{array}$ \\
\hline $\begin{array}{l}\text { Arquitetura do texto e } \\
\text { estilo de descrição }\end{array}$ & Texto aberto & Processo contínuo de revisão, releitura, recompreensão e reargumentação. \\
\hline
\end{tabular}




\begin{tabular}{|c|c|c|}
\hline \multirow{3}{*}{$\begin{array}{l}\text { Aspecto dominante do } \\
\text { processo heurístico }\end{array}$} & Cognitivo & Foco nos estados cognitivos do ator organizacional. \\
\hline & Estético & Foco nos estados estéticos que o ator organizacional expressa. \\
\hline & Emocional & Foco nos estados emocionais dos sujeitos. \\
\hline \multirow{3}{*}{ Estilos de pesquisa } & Arqueológico & $\begin{array}{l}\text { Metáfora do pesquisador como arqueólogo em busca dos fragmentos da vida } \\
\text { organizacional. }\end{array}$ \\
\hline & Lógico-empático & $\begin{array}{l}\text { Pesquisador busca o equilíbrio entre a compreensão lógico-racional e a compreensão } \\
\text { estética da vida organizacional. }\end{array}$ \\
\hline & Estético-empático & $\begin{array}{l}\text { Pesquisador "se mistura" ao ambiente organizacional e compartilha empaticamente } \\
\text { as atividades dos sujeitos organizacionais. }\end{array}$ \\
\hline
\end{tabular}

Fonte: Elaborado pelos autores.

Salientamos que essas abordagens não constituem uma tentativa de encaixotar a estética considerando seus diversos aspectos em comum. Pelo contrário, várias características da vida organizacional perpassam os limites dessas abordagens. Isso, porém, não quer dizer que elas se fundem, mas que cada uma, com suas especificidades, colabora constantemente para a condução de pesquisas criativas nos estudos sobre estética nas organizações (STRATI, 2007, 2010; STRATI e MONTOUX, 2002).

\section{CONTRIBUIÇÕES DA COMPREENSÃO EMPÁTICA PARA A PESQUISA NOS ESTUDOS ORGANIZACIONAIS}

A compreensão empático-estética, enquanto esteio epistemológico e caminho metodológico, tem muito a cooperar para a construção de pesquisas no campo dos Estudos Organizacionais dado seu caráter abrangente. A contribuição da abordagem estética da vida organizacional a partir da compreensão empática se baseia no enriquecimento do conhecimento comum e cotidiano das organizações, tendo por alicerce a apreensão da experiência estética vivida pelas pessoas enquanto elas agem. A proliferação dos estudos que trazem em seu bojo as noções da estética veio acompanhada de algumas controvérsias no tocante à opção metodológica mais adequada para a condução das pesquisas sobre a temática.

Nesse sentido, Warren (2008) apontou que os estudos que abordam a experiência vivenciada pelo pesquisador têm prevalecido na pesquisa sobre estética. Dentre essas investigações, citamos a pesquisa de Nissley, Taylor e Butler (2002), ao estudar as músicas da empresa como um discurso estético. Dessa forma, os autores se analisam na busca pelo entendimento das questões estéticas (TAYLOR e HANSEN, 2005).

De modo particular, e no contexto dos Estudos Organizacionais, sugerimos a compreensão empática como uma opção metodológica legítima para apreender os fenômenos que são cotidianamente investigados. Tendo como base o que colocamos anteriormente, essa opção metodológica tem a contribuir ao fundamentar a construção da pesquisa nos Estudos Organizacionais. Dadas as limitações de escopo e espaço neste artigo, optamos por destacar de modo manifesto a importância do papel do pesquisador, enquanto fonte de informações sensíveis para a construção do corpus de pesquisa em estética.

Nós que nos aventuramos a estudar as organizações nos achamos cotidianamente envolvidos em várias atividades sobrepostas e relacionadas. Isso ocorre por que, no decorrer da pesquisa, inevitavelmente vivenciamos as várias dimensões que compõem as organizações, incluindo a dimensão sensível, o que nos permite experimentar in loco e na própria pele as experiências que esse cotidiano nos apresenta. Essas experiências se mostram ancoradas em fragmentos da vida organizacional que acabamos por acumular durante nossa pesquisa.

Desse modo, possuímos nossas próprias experiências estéticas emersas da relação com os diversos atores organizacionais. O charme da história, o belo modo com o qual as coisas são descritas, as evocações e conjurações feitas pelos ouvintes para entender os relatos que estão sendo contados deixam fragmentos da vida organizacional impressos em nossa memória e nos nossos cadernos de anotações. Se uma história é belamente contada, por exemplo, isso irá atuar como um fator estruturante na relação entre pesquisador e sujeito organizacional e transformar esses encontros em um conjunto de experiências que serão refinadas, reconstruídas e revividas por nós pesquisadores (STRATI, 1992, 2007).

Em paralelo às nossas próprias experiências, reunimos fragmentos da vida organizacional como um leitor, que não pode ir verificar todos os eventos pesquisados. Desse modo, fenômenos como a beleza da organização, por exemplo, são compreendidos pelas experiências e pelos sentimentos dos próprios atores organizacionais ou, ainda, nas histórias contadas por membros da organização e percebidas como belas pelos outros, em um reviver de modo intuitivo daquilo que foi experimentado (STRATI, 1992). 
Assim, por não haver um distanciamento entre investigador e investigado, o pesquisador é um sujeito fundamental não só por ser aquele que vai esclarecer algo ainda encoberto, mas pelo fato de que somos nós que percebemos e sentimos por meio de nossas próprias experiências as organizações (STRATI, 1992, 1996, 2007). Isso fica ainda mais evidente quando, dentro do arcabouço empático, podemos perceber o caráter participativo de nossas ações e a capacidade de imaginarmos no lugar do outro. Dessa forma nós, enquanto pesquisadores, tomamos posição privilegiada e nos tornamos fontes válidas e legítimas de informações sensíveis por meio de nossas próprias experiências, refinando assim nossa capacidade de empatia e de construção do conhecimento estético nas organizações (STRATI, 1992, 1996, 2007).

No entanto, isso só é possível se considerarmos o exercício da ação empática. A partir do exercício da empatia, podemos compreender os motivos da ação do sujeito, com observação participante imaginada, sem a necessidade de executar a ação. Essa postura nos possibilita assumir o papel do ator organizacional, de outra pessoa envolvida na ação organizacional, ou daquele que observa a distância ou distraidamente (STRATI, 2007). Nesse sentido, o termo "observação participante imaginativa" (STRATI, 2007, p. 14) é útil para descrever a maneira como poderíamos apreender a vida organizacional, imaginando-nos nas situações descritas por outros, mesmo não estando fisicamente presentes no cenário cotidiano.

Em particular, enfatizamos as contribuições de Maffesoli (1988), ao afirmar que o projeto empático compreensivo pode figurar como divisor de águas capaz de unir, ainda que com risco, as experiências e situações que constituem a polidimensionalidade do vivido. Nesse sentido, o resgate da empatia e do senso comum, preconizado neste artigo, pode trazer apreciáveis consequências para a renovação metodológica, ao abrir o campo, integrando diferentes saberes, sejam estes sensíveis, estéticos ou lógico-racionais.

O resgate da compreensão empática abre, portanto, possibilidades enquanto método, pois não precisaríamos adotar necessariamente o ponto de vista de quem assume o papel, mas poderíamos fazê-lo com nossa imaginação que, mesmo fragmentada, revela algo acerca da vida organizacional. Além disso, não há a limitação de observar a ação organizacional sob um único ponto de vista, mas na reunião dos vários pontos de vistas envolvidos no cotidiano organizacional investigado.

\section{CONSIDERAÇÕES FINAIS}

Dentre as diversas e variadas temáticas envolvidas na área dos Estudos Organizacionais, a estética se apresentou enquanto metáfora epistemológica para o estudo das organizações. Dessa maneira, compreender os aspectos subjetivos concernentes à experiência estética por meio da qual os sujeitos adquirem o conhecimento sensível se mostra necessário, como forma de ampliar a compreensão das ações dos sujeitos e seus reflexos no contexto em que estão inseridos, dentre eles as organizações. Nesse sentido, e partindo do conceito de estética nas organizações, enquanto conhecimento obtido por meio dos sentidos e do juízo estético, questões metodológicas foram levantadas no que diz respeito às opções de como investigar a estética nas organizações.

Para apreendermos e compreendermos o sensível que reside nas percepções do sujeito organizacional, algo que não pode ser mensurado pelos métodos lógico-racionais de condução da pesquisa, são necessárias formas refinadas de exame da realidade para entender o outro a partir de sua perspectiva estética.

Nesse sentido, resgatamos e desvelamos a compreensão empática enquanto arcabouço teórico-metodológico promissor à pesquisa da estética da vida organizacional. Por consistir em se colocar no lugar do outro, essa opção metodológica facilita a pesquisa de algo tão fugaz e particular como a experiência estética. Assim, objetivamos com este estudo discutir a compreensão empática como uma metodologia legítima para o estudo da estética organizacional, bem como trazer à luz insights de possíveis contribuições dessa metodologia não somente na seara da estética, mas no campo dos Estudos Organizacionais. Para tanto, traçamos um panorama da compreensão empática, a partir de suas bases sociológicas weberianas até sua discussão enquanto opção metodológica na pesquisa sobre estética, segundo Strati (1992).

Dentre os aspectos evidenciados, destacamos a legitimação do pesquisador enquanto fonte válida de informações sensíveis, além da lógico-racional para a composição do corpus de pesquisa; a possibilidade deste se integrar ao contexto que se almeja estudar por meio do método da empatia e a flexibilidade que perpassa a metodologia da compreensão empática a partir dos estilos de pesquisa. Estes permitem adequar o grau de envolvimento do pesquisador ao contexto estudado, bem como ajustar a abordagem aos objetivos de pesquisa.

Destarte, as discussões articuladas neste artigo sustentaram que a compreensão empática se apresenta como uma opção teórico-metodológica que pode contribuir para a pesquisa no campo dos Estudos Organizacionais, especialmente por ser capaz de abrir e ampliar o campo em estudo e apreender o conhecimento comum cotidiano que os métodos de investigação lógico-racionais dificilmente captam. Por fim, esperamos que este estudo sirva de gatilho para a elaboração de outras discussões temáticas, além da estética organizacional, fomentando a reflexão a respeito das questões metodológicas relacionadas à compreensão empática nos Estudos Organizacionais. 
Compreensão empática e as possíveis contribuções para a pesquisa nos estudos organizacionais: reflexões a partir da experiência do lado estético das organizações
Luma Louise Sousa Lopes | Ana Sílvia Rocha Ipiranga José Jorge da Silva Júnior

\section{REFERÊNCIAS}

ABEL, T. The operations called Verstehen. American Journal of Sociology, v. 54, n. 3, p. 211-218, 1948.

ARISTÓTELES. Poética. São Paulo: Editora Abril, 1984.

BAUMGARTEN, A. G. Estética: a lógica da arte e do poema. Petrópolis, RJ: Vozes, 1993.

BERG, P. O. Some notes on corporate artifacts. Scos Note-Works, v. 6, n. 1, p. 24-28, 1987.

BIHEL-MISSAL, B. Using artistic form for aesthetic organizational inquiry: Rimini Protokoll constructs Daimler's General Meeting as a theatre play. Culture and Organization, v. 18, n. 3, p. 211-229, 2012.

BOLOGNINI, B. Images as identifying objects and as organizational integrators in two firms. Dragon, v. 1, n. 3, p, 61-75, 1986.

BURREL, G.; MORGAN, G. Sociological paradigms and organisational analysis. Surrey, England: Ashgate publishing Limited, 1979

BOUILLOUD, J. P.; DESLANDES, G. From negativity to creativity: about the aesthetics of "Beau Geste" in leadership. In: EUROPEAN GROUP FOR ORGANIZATIONAL STUDIES COLLOQUIUM, 29., Montreal. Proceedings... Montreal: [s. n], 2013.

CAMARA, L. Ecos da contribuição de Guereiro Ramos para a divulgação da obra de Weber no campo de Estudos Organizacionais. In: ENCONTRO DE ESTUDOS ORGANIZACIONAIS, 6., 2010, Belo Horizonte, Anais... Belo Horizonte: AnPAD, 2010.

COSTA, J. Toward a signaletic symbology of identity in corporate communication. Dragon, v. 1, n. 5, p. 5-16, 1986.

CSILLAG, P. A experiência estética em organizações criativas: uma investigação fenomenológica do impacto da percepção visual sobre a criatividade. 203 f. Tese (Doutorado em Administração) - Escola de Administração de Empresas de São Paulo, Fundação Getulio Vargas, São Paulo, 2003.

DEGÒT, V. Portrait of the manager as an artist. Dragon, v. 2, n. 3, p. 13-50, 1987.

FILIPPI, M.; TANNERY, F. Aesthetics drama and strategy creation. In: EUROPEAN GROUP FOR ORGANIZATIONAL STUDIES COLLOQUIUM, 25., 2009, Barcelona. Proceedings... Barcelona: [s.n], 2009.

FLORES-PEREIRA, M. T. Corpo, pessoa e organização. Organizações \& Sociedade, v. 17, n. 54, p. 417-438, 2010.

GAGLIARDI, P. Explorando o lado estético da vida organizacional. In: CLEGG, S. R.; HARDY, C.; NORD, W. R. Handbook de estudos organizacionais. São Paulo: Atlas, 2009. v. 2., p. 127-146.

GRAFTON-SMALL B.; LINSTEAD, S. Bricks and bricolages: deconstructing corporate images in stone and story. Dragon, v. 1, n. 1, p. 8-27, 1985.

GRIMM, S. The value of understanding. Philosophy Compass, v. 7, n. 2, p. 103-117, 2012.

IPIRANGA, A. S. R.; LOPES, L. L. S.; SOUZA, E. M. A experiência estética nas práticas culinárias de uma organização gastronômica. Organizações \& Sociedade, v. 23, n. 77, p. 191-210, 2016.

KANT, I. Crítica da faculdade do juízo. 3. ed. Rio de Janeiro: Forense Universitária, 2012.

KURONEN, T. Aesthetics of knowledge in organizations. In: EUROPEAN GROUP FOR ORGANIZATIONAL STUDIES COLLOQUIUM, 28., Helsinque. Proceedings... Helsinque: [s.n], 2012.

LEAL, R. S. Contribuições da estética para a análise organizacional: a abordagem de uma dimensão humana esquecida. In: ENCONTRO
DE ESTUDOS ORGANIZACIONAIS, 1., 2000, Curitiba. Anais... Curitiba: AnPAD, 2000.

LEAL, R. S. Razão, práxis e estética: integração de diferentes dimensões de análise organizacional. In: ENCONTRO DA ASSOCIAÇÃO NACIONAL DE PÓS-GRADUAÇÃO E PESQUISA EM ADMINISTRAÇÃO, 26., 2002, Salvador. Anais... Salvador: AnPAD, 2002.

LEAL, R. S. A estética como elemento para a compreensão da criatividade nas organizações. Organizações \& Sociedade, v. 14, n. 42, p. 67-82, 2007.

LEAL, R. S.; ROCHA, N. M. F. Estética, valores e cultura: ampliando a subjetividade na análise organizacional. In: ENCONTRO DE ESTUDOS ORGANIZACIONAIS, 5., 2008, Belo Horizonte. Anais... Belo Horizonte: AnPAD, 2008.

LOPES, L. L. S. Sabores do cotidiano: a experiência estética nas práticas culinárias de uma organização gastronômica. 168 f. Dissertação de Mestrado (Mestrado em Administração) - Universidade Estadual do Ceará, Fortaleza, 2014.

LOPES, L. L. S.; SOUZA, E. M.; IPIRANGA, A. S. R. Desvelando as categorias estéticas na organização de um pequeno restaurante. Revista Interdisciplinar de Gestão Social, v. 3, n. 1, p. 207-222, 2014.

MACK, $K$. Taking an aesthetic risk in management education: reflections on an artistic-aesthetic approach. Management Learning, v. 44, n. 3, p. 286-304, 2013.

MAFFESOLI, M. O conhecimento comum. Compêndio de sociologia compreensiva. São Paulo: Brasiliense, 1988.

MARTIN, P. Y. Sensations, bodies, and the 'spirit of a place': aesthetics in residential organizations for the elderly. Human Relations, v. 55, n. 7, p. 861-885, 2002.

MATTOS, P. C. C. L. “Os resultados desta pesquisa (qualitativa) não podem ser generalizados": pondo os pingos nos is de tal ressalva. Cadernos EBAPE.BR, v. 9, p. 450-468, 2011.

MONTE, A. L. A.; MESQUITA, R. F. A objetividade do conhecimento científico à luz do pensamento de Max Weber e Karl Poper. In: ENCONTRO DA ASSOCIAÇÃO NACIONAL DE PESQUISA E PÓSGRADUAÇÃO EM ADMINISTRAÇÃO, 38., 2013, Rio de Janeiro. Anais... Rio de Janeiro: AnPAD, 2013.

MUNCH, P. A. Empirical science and Max Weber's Verstehen de Soziologie. American Sociological Review, v. 22, n. 1, p. 26-32, 1957.

NISSLEY, N.; TAYLOR, S. S.; BUTLER, O. The power of organizational song: an organizational discourse and aesthetic expression of organizational culture. Tamara: Journal of Critical Postmodern Organization Science, v. 2, n. 1, p. 46-62, 2002.

OLIVEIRA, L. Y. M. de. A arquitetura dos processos de aprendizagem à luz da teoria da estética organizacional. 175 f. Dissertação (Mestrado em Administração) - Escola de Administração, Universidade Federal do Rio Grande do Sul, 2012.

OTTENSMEYER, E. J. Too strong to stop, too sweet to lose: aesthetics as a way to know organizations. Organization, v. 3, n. 2, p. 189-194, 1996.

PAIVA, L. H. Weber e Popper: filosofia das ciências sociais. Piracicaba, SP: Ed. Unesp, 1997.

PELZER, P. Disgust and organization. Human Relation, v. 55, n. 7, p. 841-860, 2002.

PEUKERT, $\mathrm{H}$. Beyond the present state of affairs: Bildung and the search for orientation in rapidly transforming societies. Journal of Philosophy of Education, v. 36, n. 3, p. 421-435, 2002. 
Compreensão empática e as possíveis contribuções para a pesquisa nos estudos organizacionais: reflexões a partir da experiência do lado estético das organizações
Luma Louise Sousa Lopes | Ana Sílvia Rocha Ipiranga José Jorge da Silva Júnior
PLATÃO. A República. 7. ed. Lisboa: Fundação Calouste Gulbenkian, 1993.

POKER, J. G. A. B. Os sentidos de compreensão nas teorias de Weber e Habermas. Trans/Form/Ação, v. 36, p. 221-244, 2013.

RAMIREZ, R. An aesthetics theory of social organization. Dragon, v. 2, n. 3, p. 51-64, 1987a.

RAMIREZ, R. The relationship between the aesthetics theory of social organization and some theories of organizational symbolism. Dragon, v. 2, n. 3, p. 65-84, 1987b.

RAMIREZ, R. Wrapping form and organizational beauty. Organization, v. 3, n. 2, p. 233-242, 1996.

RINGER, F. A metodologia de Max Weber: unificação das ciências culturais e sociais. São Paulo: Edusp, 2004.

RUSTED, B. Aesthetic decisions as organizational practice. Dragon, v. 2, n. 4, p. 127-138, 1987.

SCHELER, M. Visão filosófica do mundo. São Paulo: Perspectiva, 1986.

SCHIAVO, S. R. As práticas de trabalho e o processo de aprendizagem de trabalhadores da construção civil à luz da estética organizacional. 107 f. Dissertação (Mestrado em Administração) - Escola de Administração, Universidade Federal do Rio Grande do Sul, Porto Alegre, 2010.

SCHNEIDER, S. C.; POWLEY, E. The role of images in changing corporate culture: the case of AT\&T. Dragon, v. 1, n. 2 p. 5-44, 1985.

SORENSEN, B. M. St. Paul's conversion: the aesthetic organization of labour. Organization Studies, v. 31, n. 3, p. 307- 326, 2010.

STEPHENS, J. P.; BOLAND, B. Legitimizing convergence: aesthetics as a bridge between managing and designing. In: EUROPEAN GROUP FOR ORGANIZATIONAL STUDIES COLLOQUIUM, 27., 2011, Gotemburgo. Proceedings... Gotemburgo: [s.n], 2011.

STRATI, A. Aesthetics understanding of organizational life. Academy of Management Review, v. 17, n. 3, p. 568-581, 1992.

STRATI, A. Organizations viewed through the lens of aesthetics. Organization, v. 3, n. 2, p. 209-218, 1996.

STRATI, A. Putting people in the picture: art and aesthetics in photography and in understanding organizational life. Organization Studies, v. 21, n. 1, p. 53-69, 2000.
STRATI, A. Organização e estética. Rio de Janeiro: Ed. FGV, 2007.

STRATI, A. Aesthetics understanding of work and organizational life: approaches and research developments. Sociology Compass, v. 10, n. 4, p. 880-893, 2010.

STRATI, A.; MONTOUX, P. G. de. Introduction: organizing aesthetics. Human Relations, v. 55, n. 7, p. 755-766, 2002.

TAVARES, M. G. P.; KILIMNIK, Z. M. O conhecimento estético pode ser uma forma de explicação do conhecimento tácito? Reflexões a partir de dados empíricos. In: ENCONTRO DE ADMINISTRAÇÃO DA INFORMAÇÃO, 1., 2007, Florianópolis. Anais... Florianópolis: AnPAD, 2007.

TAYLOR, S. S. Overcoming aesthetic muteness: researching organizational members' aesthetic experience. Human Relations, v. 55, n. 7, p. 821-840, 2002.

TAYLOR, S. S.; HANSEN, H. Finding form: looking at the field of organizational aesthetics. Journal of Management Studies, v. 42, n. 6, p. 1211-1231, 2005.

WARREN, S. Empirical challenges in organizational aesthetics research: towards a sensual methodology. Organization Studies, v. 29, n. 4, p. 559-580, 2008.

WASSERMAN, V.; FRENKEL, M. Organizational aesthetics: caught between identity regulation and culture jamming. Organizational Science, v. 22, n. 2, p. 503-521, 2011.

WEBER, M. Sobre a teoria das ciências sociais. 3. ed. Lisboa: Presença, 1979.

WEBER, M. Conceitos básicos de sociologia. 5. ed. São Paulo: Centauro, 2008.

WEBER, M. Economia e sociedade: fundamentos da sociologia compreensiva. 4. ed. São Paulo: Ed. UnB, 2012. v. 1.

WHITE, D. A. 'It's working beautifully!' Philosophical reflections on aesthetics and organization theory. Organization, v. 3, n. 2, p. 195208, 1996.

WIERZBICKA, A. Understanding other requires shared concepts. Pragmatics and Cognition, v. 20, n. 2, p. 356-379, 2012.

WOOD, T.; CSILLAG, P. Estética organizacional. Organização \& Sociedade, v. 8, n. 21, p. 35-44, 2001.

Luma Louise Sousa Lopes

Doutoranda em Administração no Programa de Pós Graduação da Universidade Estadual do Ceará (PPGA/UECE); Professora na Universidade Estadual do Ceará (UECE), Fortaleza - CE, Brasil. E-mail: lumalouise@gmail.com

Ana Sílvia Rocha Ipiranga

Doutora em Psicologia do Trabalho e da Organização pela Università degli Studi di Bologna (Itália); Professora na Universidade Estadual do Ceará

(UECE), Fortaleza - CE, Brasil. E-mail: ana.silvia@pq.cnpq.br

José Jorge da Silva Júnior

Mestre em Administração no Programa de Pós Graduação da Universidade Estadual do Ceará (PPGA/UECE); Professor na Universidade Estadual do Ceará (UECE), Fortaleza - CE, Brasil. E-mail: jorge@zejorge.com 